\title{
Morar e Conviver
}

\author{
Alfredo José Gonçalves*
}

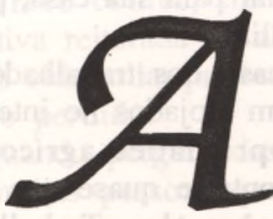

$s$ reflexões que se seguem nasceram a partir de um trabalho pastoral junto a com unidades eclesiais da periferia de São Paulo, mais especificamente algumas favelas do Parque Santa Madalena, zona leste da cidade. Não se trata propriamente de um artigo, e sim de alguns comentários a respeito do conceito morar, relacionando-o à convivência numa população com elevado número de migrantes.

\section{Casa e Sobrevivência}

Morar inclui pelo menos três componentes básicos: casa, vizinhança e rede de sobrevivência. Quando dizemos "casa", queremos entender o espaço físico, a base material da habitação. Em termos concretos, as paredes, o telhado, o piso - local onde se abriga a chamada familia nuclear. Trata-se, em síntese, dos poucos metros quadrados onde se escondem - para utilizar uma expressão popular e de nenhuma forma destituída de sentido - um ou mais grupos familiares. Nesta denominação incluem-se ainda, se houver, horta, área de serviço, garagem, jardim. Posse ou propriedade legalizada, é em geral limitada por um muro ou uma cerca. Espaço que, muitas vezes, é designado como terreno ou terreninho, começando e terminando, muito precisamente, onde começa e termina o do vizinho.

"Vizinhança" é algo menos preciso que se estende para além do terreno. Em contraposição a casa, refere-se ao ambiente externo. Irradiando-se a partir do centro, amplia-se em raios desiguais de acordo com o relacionamento. Podemos imaginar um círculo de limites diferenciados, de acordo com maior ou menor grau de amizade interpessoal ou inter-familiar. A expressão todo mundo aqui me conhece, ou inversamente, conheço todo mundo deste lugar, refere-se a esse círculo. Ao redor e a partir da casa, ele abrange a rua, a vila, o bairro. A rigor, não há contornos geográficos, seus limites são uma espécie de esfera relacional que dá conta dos laços familiares extensivos , tais como parentesco e compadrio. Dá conta, igualmente, do saber popular a respeito da saúde e da medicina caseira. E dá conta, finalmente, das relações que se criam para além da casa e que se ampliam de forma seletiva, criando no interior do círculo pontos de apoio para as mais variadas circunstâncias.

A vizinhança pode ainda crescer por influência da participação em movimentos reivindicatórios, em comunidades religiosas de diferentes credos, bem como nas organizações de base $\mathrm{e}$ nas lutas populares. Esta relação, entretanto, não é mecânica. Vizinhança e organização nem sempre se misturam com a facilidade que muitas vezes se espera. Chegam até a excluir-se, caso em que a primeira tende a funcionar como um escudo que serve de proteção frente a compromissos de exigências políticas.

Em poucas palavras, entende-se por vizinhança a base territorial que circunda a casa, estendendo-se seletivamente conforme a esfera de relações. Constitui um círculo de contornos irregulares, podendo sempre abrir-se a novos conhecimentos, ou fechar-se aos antigos. Este depoimento de um morador de favela caracteriza bem o conceito: "Eu quase nunca estou em casa. De semana trabalho, e de fimde-semana visito os amigos e conhecidos. Pra ficar em casa, só se for em caso de doença".

A "rede de sobrevivência", finalmente, inclui e pressupõe os dois conceitos acima. Refere-se basicamente às relações criadas com vistas à sobrevivência do grupo familiar. Tem por finalidade reforçar a renda mensal, diante dos baixos salários ou do desemprego. Excluem-se destas relações os empregos regulares, registrados em carteira.

Trata-se em geral de prestação de serviços de caráter remunerado, seja na construção e ampliação da casa; seja através de um comércio de sorve- tes, doces, bijuterias, roupas, etc.; seja de conserto de eletrodomésticos; seja pela coleta de ferro, papelão e outros materiais aproveitáveis; seja, enfim, por aquilo que no jargão popular se designa como bico. Frequentes vezes esses serviços respondem por grande parte da renda familiar, quando não pela sustentação integral da família. Tais bicos, predominantemente, são atribuições das mulheres e das crianças, encontrando-se menores de idade responsáveis únicos pelo suprimento de toda a familia. Contudo, em virtude do elevado nível de desemprego, cada vez mais os homens passam também a exercer esses trabalhos. Da relação entre casa, familia e vizinhança depende, não poucas vezes, a rede de sobrevivência. Esta terá alicerces tanto mais sólidos quanto maior o conhecimento que se adquire na vila ou bairro.

Há inclusive casos em que a rede bem "lubrificada" rende melhores ganhos do que um emprego regular. Dependendo do grau de relacionamento que se estabelace entre a casa e a vizinhança, pode haver vantagem em permanecer desempregado. Em outras palavras, o "desemprego" pode constituir não apenas uma estratégia de sobrevivência, mas também uma forma de resistência à dominação entre patrão e empregado. É notável, por exemplo, o sonho do migrante nordestino em ser autônomo, como também, por outro lado, sua resistência ao relógio de ponto.

Casa, vizinhança e rede de sobrevivência - três componentes do morar formam um todo dinâmico. Movendose numa extensa rede de informações e relacionamentos, de maior ou menor calor humano e social, sujeito sempre a ampliação e retraimento, a família se sente em casa. Neste caso, a palavra casa inclui todo esse habitat que é construido, reforçado e alinhavado por invisiveis fios de relações humanas. Trata-se de um processo que requer sacrifício, argúcia, muita esperteza e, por que não grande dose de sacanagem. Luta cotidiana, miúda e secreta, pela conquista de espaços e pessoas. 
Um permanente equilibrar-se, precária e perigosamente, sobre a corda bamba da subsistência. Este esforço para cavar o pão de cada dia, às vezes literalmente o de-comer, exige enorme perspicácia e uma espécie de sabedoria que somente a carência prolongada é capaz de ensinar. Depende também da correlação que se puder estabelecer entre os três componentes acima.

Até mesmo os casos mais graves, que vivem pendurados na caridade dos vizinhos, na esmola ou na cesta da comunidade, têm sua possibilidade de sobrevivência em parte determinada por tal relação. Afinal de contas, o vizinho nem sempre está disposto a subtrair de sua compra mensal o tradicional "quilo da caridade", ou melhor, nem sempre pode fazê-lo sem comprometer a sua própria mesa.

A importância que adquire para a família cada um desses componentes está relacionada, por outro lado, com a renda familiar e o consequente nível de vida. Tentamos na sequência ver isso mais de perto.

\section{Moradia e Nível de Vida}

Se imaginarmos uma trajetória no sentido periferia-centro, na qual, ainda que de forma não linear, o nível de vida vai crescendo, poderemos constatar graus diferenciados de importância para cada um dos elementos acima. Assim, ao passo que um morador de favela, por exemplo, confere enorme relevância ao relacionamento com a vizinhança em detrimento da casa, o morador de uma habitação de alvenaria acentua vivamente a importância da casa, reduzindo a da vizinhança. $\mathrm{Na}$ medida em que nos aproximamos do centro - pensado em termos não tanto geográficos mas de poder aquisitivo - a casa vai se tornando cada vez mais relevante, enquanto que a vizinhança é deixada num segundo plano.

Uma moradia precária demais, miserável mesmo, como um barraco ou quarto de cortiço, tende a levar seus moradores a se fixarem nas relações externas, como forma de compensar ou até mesmo de fugir ao espaço exíguo e sórdido. Já uma mansão bem equipada, abstraindo-se aqui de outros fatores de ordem moral, humana ou psíquica, tende a fixar seus membros no espaço interno, por encontrarem aí, evidentemente, toda comodidade e

conforto de que necessitam. Verificase, assim, que a sociabilidade com os moradores imediatamente vizinhos pode aumentar ou diminuir de acordo com a renda familiar, com o padrão de vida e, consequentemente, com o tipo de casa. Cresce a sociabilidade imedia-

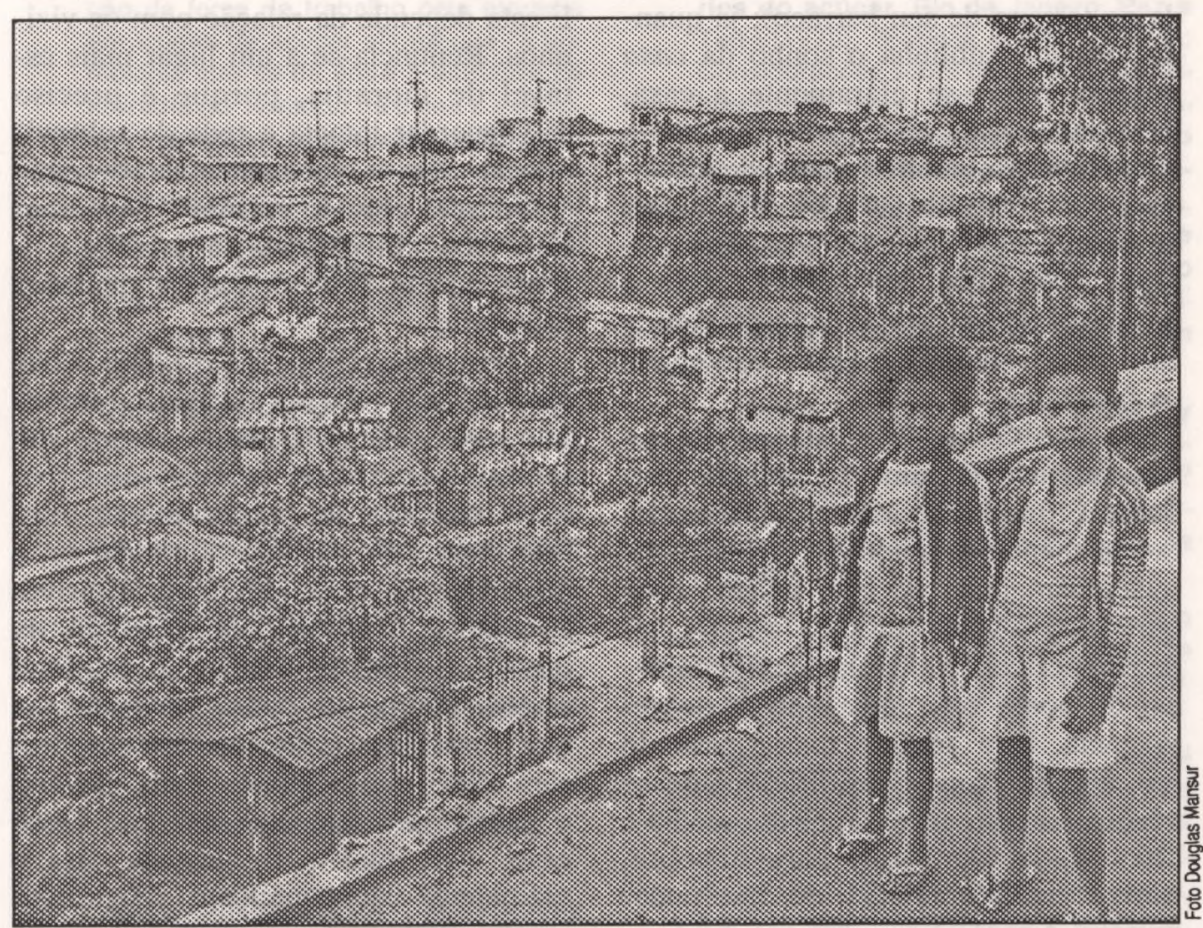

ta na medida em que decresce o nível de vida. Até porque em bairros abastados os componentes da familia não necessitam sair à rua e bater de porta em porta para buscar diariamente a sobrevivência. Dispõem de outros meios. Quanto àqueles de nível médio, uma colocação estável no mercado de trabalho lhes dá a segurança necessária, sendo a casa um dos frutos desta estabilidade. Já o morador de periferia ou de favela, como também do centro pobre, instavelmente empregado ou desempregado, agarra-se de todos os modos à vizinhança como garantia de sobrevivência.

Nos bairros pobres, o círculo de vizinhança localiza-se numa zona bem mais imediata a casa. À medida que cresce o nível de vida, ele tende a se distanciar. Amplia-se a circunferência e as relações se tornam mais ralas. Assim, a vizinhança, essa esfera relacional, é relativamente contínua nas regiões pobres e bem mais descontínua nos bairros de classe média e alta. A explicação não é difícil: enquanto uns dispõem de dinheiro, carro e telefone para ampliar ao máximo o círculo de vizinhança, a maioria tem apenas os pés e o transporte coletivo. Os primeiros podem se dar ao luxo de escolher os seus "vizinhos", ao passo que os outros têm que aprender a conviver com os que the são "vizinhos". Vê-se que a palavra vizinho pode ter diferentes co- notações, significando aquele que mora ao lado ou aquele com quem se estabelece um relacionamento mais intenso.

Há portanto estreita relação entre moradia, nível de sociabilidade e padrão de vida. Relação que se torna mais evidente quando se trata de mudar. E sabemos como, sobretudo entre as camadas mais pobres, é frequente a migração dentro da própria cidade. Nestes casos de mudança fica mais claro o grau diferenciado de importância de cada um dos componentes do morar.

\section{Dilema de Mudar}

Em conversa recente, dizia um morador de favela: "Adoro morar aqui. Por nada deste mundo eu deixaria este lugarzinho". Logo em seguida, entretanto, perguntado sobre a possibilidade de obter financiamento para a compra de um lote urbanizado, respondeu sem vacilar: "Esse é o meu sonho, o meu maior sonho. Desde que vim do Paraná para São Paulo, vivo sonhando com a casa própria. Se Deus quiser, um dia a gente consegue". 
Distingue-se nitidamente duas coisas: quando afirma que não quer deixar o seu lugarzinho, está se referindo ao círculo de vizinhança e à rede de sobrevivência (o morador em questão, além de trabalhar como lavador numa firma do Ipiranga, comercializa madeira usada no terreno de seu barraco); já quando insiste e sublinha o sonho da casa própria, refere-se claramente a casa, base material da residência. Daí que a administração pública vem encontrando sérias dificuldades para a remoção de barracos em risco na beira dos córregos e encostas dos morros. Nem a promessa de em pouco tempo adquirir casa de alvenaria consegue convencer os favelados.

O problema está justamente na transferência de uma localidade para outra. É mais vantajoso permanecer na favela mantendo intocável a esfera de relacionamentos, do que, mesmo conquistando o sonho da casa própria, ter de romper com a vizinhança e recomeçar do ponto zero toda rede de sobrevivência. Esta adquire maior peso do que a casa. Coisa que dificilmente se verificaria com gente de classe média e alta. Mudar de lugar, para o pobre, torna-se mais dramático do que mudar de casa. A razão é simples: na vizinhança reside a segurança de seu futuro. $\mathrm{O}$ mesmo se comprova se atentarmos para a quantidade de vezes que um favelado, por exemplo, costuma transferir-se de barraco, desde que, e somente desde que permaneça na mesma favela, ou pelo menos no mesmo bairro. Chega ao ponto de, vendendo e comprando seguidamente o próprio barraco, fazer desse comércio um meio de vida.

Para aquele que vive de "bico" ou da caridade dos vizinhos, importa menos trocar de casa do que trocar de vizinhança. Enquanto, no primeiro caso, é relativamente fácil arrumar outro "buraco para se esconder", no segundo, é muito difícil e demorado recriar toda a rede de convivência. Isto porque "vizinhança é assim: ou você tá de bem com ela, ou você tá perdido" - dizia ainda há pouco outro morador. Para quem depende de um suprimento que reforce o baixo salário ou para quem depende unicamente desse reforço, o isolamento dos vizinhos pode ser fatal.

Em tempos de catástrofes - enchentes, por exemplo - é comum verificar-se o mesmo. Muitas vezes as famílias atin- gidas, tendo sido removidas e assentadas em locais mais seguros, acabam desfazendo-se com certa facilidade do seu novo barraco e retornando ao lugar de origem, mesmo em condições bem mais precárias. Claro, em primeiríssimo lugar está em jogo a sobrevivência. E esta depende da relação com os vizinhos. Renuncia-se a um lugar mais estável de moradia, porque é preciso salvaguardar intacta a rede de sobrevivência. Sem a casa, ainda se consegue "empurrar com a barriga". Mas sem uma boa convivência, a miséria e a fome podem bater à porta a qualquer momento.

Tem mais valor para o pobre o círculo de suas relações do que o terreninho onde provisoriamente ergueu sua tenda. Alguém de poder aquisitivo mais elevado se surpreenderá com isso. Para este, na hora de mudar-se, a qualidade da casa tem peso decisivo. Escolhe-se o bairro pela qualidade da nova moradia. O carro e o telefone podem facilmente cobrir as distâncias que a mudança acarretou. E a surpresa será tanto maior quanto mais elevado o padrão de vida, uma vez que nesse caso, com relativa frequência, casa e vizinhança não coincidem geograficamente. Pode-se fixar residência numa localidade e construir em outra as relações de vizinhança. A locomoção, que para o pobre é um problema, aqui é irrelevante. No caso dos setores populares, é absolutamente imprescindível que as duas coisas coincidam, se possível na mesma favela ou bairro. Não se pode depender do transporte coletivo para a criação e manutenção dessa rede. Já basta ter que fazer isso diariamente no deslocamento ao trabalho.

\section{Concluindo}

Moradia, em seus três componentes, constitui um conceito unitário e indivisivel. Mais do que fixar-se em determinado local, morar significa sobreviver humana, social e psiquicamente. Numa palavra, é viver. Daí a extrema importância da rede de saúde, por exemplo. Especialmente entre as camadas mais pobres da população, essa rede adquire acentuado valor. De entre todos os relacionamentos efetuados, mantidos e reforçados, é sem dúvida esse "saber que cura" aquele que ganha maior importância. Estando os sistemas de saúde fora do alcance dessas camadas - tanto o público quanto o privado - apela-se com unhas e dentes para o "benzimento" e a sabedoria popular que está por trás dele.

Em síntese, no processo migratório pode tornar-se extremamente mais difícil desfazer-se dos amigos, dos compadres, dos conhecidos, dos parentes toda a gama de relações inter-pessoais e inter-grupais - do que perder a terra ou a casa. Terra e casa, "com a ajuda de Deus e dos amigos, a gente consegue", enquanto que começar ou recomeçar uma rede de vizinhança é um processo trabalhoso. Custa muita "saliva" e muito sacrifício.

Não é sem razão que uma das preocupações dos migrantes na cidade grande, e não a última, é refazer os laços familiares de origem. Através de várias etapas migratórias e da vinda progressiva dos componentes, procura-se recompor o parentesco da região de origem. Nas favelas e bairros pobres, é comum encontrar-se grupos inteiros não só de uma mesma família, o que seria bem compreensível, mas também de uma mesma cidade.

Trata-se de transplantar a vizinhança, complementando a moradia provisóriamente quebrada pela migração. Juntamente com a conquista de uma nova casa (no bairro, na favela ou no cortiço), recompõe-se a unidade desfeita. Enquanto não se consegue isso, a carta substitui o contato pessoal no reforçamento da rede de vizinhança.

Ao cair no anonimato da cidade grande, os migrantes têm necessidade de manter essa rede na luta pela sobrevivência. Através de idas e vindas sucessivas, vão desfazendo e refazendo os fios invisiveis da rede, não descansando enquanto "toda a parentada não estiver novamente reunida". Muitos núcleos da periferia de São Paulo e seguramente de outras cidades grandes - têm sua origem nesse esforço dos migrantes para alinhavar os laços rompidos.

Assim, o círculo de convivência tem contornos permanentemente móveis, alargando-se e estreitando-se de acordo, também, com os caminhos e descaminhos da migração.

- Alfredo J. Gonçalves é sacerdote, Diretor do Centro de Estudos Migratórios e Secretário Executivo do Serviço Pastoral dos Migrantes. 